\title{
Pembinaan dan Penyuluhan terhadap Kader tentang Pengelolaan Posyandu Di Posyandu Cempaka Putih Desa Kolot Kelurahan Linggasari Kecamatan Ciamis
}

\author{
Lusi Lestari ${ }^{1}$, Lia Purwaningsih ${ }^{2}$, Lita Sari $^{3}$, Rike Mulyani ${ }^{4}$ \\ ${ }^{1}$ Dosen STIKes Muhammadiyah Ciamis \\ ${ }^{2,3,4}$ Mahasiswa STIKes Muhammadiyah Ciamis \\ Email: lusilestari.1987@gmai.com
}

\begin{abstract}
ABSTRAK
Posyandu merupakan salah satu bentuk upaya kesehatan bersumber daya masyarakat (UKBM) yang dikelola dari, oleh, untuk dan bersama masyarakat, guna memberdayakan masyarakat dan memberikan kemudahan masyarakat dalam memperoleh pelayanan kesehatan dasar. Upaya peningkatan peran dan fungsi posyandu bukan semata-mata tanggungjawab pemerintah saja, namun semua komponen yang ada di masyarakat, termasuk kader. Peran kader dalam penyelenggaraan posyandu sangat besar karena selain sebagai pemberi informasi kesehatan kepada masyarakat untuk datang ke posyandu dan melaksanakan perilaku hidup bersih dan sehat. Kelurahan Linggasari merupakan salah satu kelurahan yang ada di Kecamatan Ciamis Kabupaten Ciamis, yang memiliki potensi yang cukup baik tentang keberadaan posyandu. Jumlah posyandu di Kelurahan Linggasari sebanyak 8 posyandu. Posyandu Cempaka Putih merupakan salah satu posyandu yang ada di Kelurahan Linggasari. Posyandu tersebut masih dalam tarap perkembangan yang memerlukan binaan. Berdasarkan hal tersebut maka diperlukan adanya bantuan untuk pengembangan posyandu dengan melakukan pengabdian masyarakat yaitu melalui pembinaan dan penyuluhan kepada kader tentang pengelolaan posyandu yang dilaksanakan dari tanggal 27 November 2017 sampai dengan 03 Januari 2018.
\end{abstract}

Kata kunci : Pembinaan, Penyuluhan, Posyandu dan Kader

\section{ABSTRACT}

IHC is one form of community-sourced health efforts (UKBM) managed from, by, for and with the community, to empower the community and provide facilities for the community to obtain basic health services. Efforts to improve the role and function of IHC are not merely the responsibility of the government, but all components in the community, including cadres. The role of cadres in the implementation of IHC is very large because in addition to being a provider of health information to the community to come to the IHC and carry out clean and healthy life behaviors. Linggasari is one of the villages in Ciamis Sub-District, Ciamis Regency, which has good potential about the existence of IHC. The number of IHC in Linggasari Village are 8 units. Cempaka Putih is one of the IHC in Linggasari Village. The IHC is still in progress, which requires assistance. Based on the situation, it is necessary to have assistance for the development of it by conducting community service, namely through fostering and counseling cadres on the management of IHC that is carried out from November 27, 2017 to January 03, 2018.

Keywords: Development, Elucidation, IHC, Cadres 


\section{PENDAHULUAN}

Posyandu merupakan salah satu bentuk upaya kesehatan bersumber daya masyarakat (UKBM) yang dikelola dari, oleh, untuk dan bersama masyarakat, guna memberdayakan masyarakat dan memberikan kemudahan masyarakat dalam memperoleh pelayanan kesehatan dasar. Upaya peningkatan peran dan fungsi posyandu bukan semata-mata tanggungjawab pemerintah saja, namun semua komponen yang ada di masyarakat, termasuk kader. Peran kader dalam penyelenggaraan Posyandu sangat besar karena selain sebagai pemberi informasi kesehatan kepada masyarakat untuk datang ke posyandu dan melaksanakan perilaku hidup bersih dan sehat (Kementerian Kesehatan RI, 2012: 1).

Agar posyandu melakukan fungsi dasarnya, dimana posyandu mempunyai daya ungkit yang sangat besar terhadap penurunan angka kematian bayi, angka kematian balita dan angka kematian ibu, maka perlu adanya upaya memantau dan mendorong tingkat perkembangan Posyandu (Ambarwati dan Sismintari, 2015). Jumlah posyandu di Kabupaten Ciamis dari tahun ke tahun selalu meningkat, pada tahun 2017 jumlah Posyandu tercatat 1.599 buah (Dinas Kesehatan Kabupaten Ciamis, 2017 : 153 ). Secara keseluruhan meningkat 13 Posyandu dibanding tahun 2014 yang berjumlah 1.586 buah (Dinas Kesehatan Kabupaten Ciamis, 2014 : 142). Dengan meningkatnya jumlah Posyandu tersebut dapat membantu dalam pencapaian pembangunan kesehatan ibu dan anak.

Kelurahan Linggasari merupakan salah satu kelurahan yang ada di Kecamatan Ciamis Kabupaten Ciamis, yang memiliki potensi yang cukup baik tentang keberadaan posyandu. Jumlah posyandu di Kelurahan Linggasari sebanyak 8 posyandu (Profil Kelurahan Linggasari, 2016). Posyandu Cempaka Putih merupakan salah satu posyandu yang ada di Kelurahan Linggasari. Posyandu tersebut masih dalam tarap perkembangan yang memerlukan binaan. Berdasarkan hal tersebut maka kami Prodi D III Kebidanan akan membantu pengembangan posyandu dengan melakukan pengabdian masyarakat yaitu melalui pembinaan dan penyuluhan kepada kader tentang pengelolaan posyandu.

\section{BAHAN DAN METODE}

Pengabdian kepada masyarakat dilaksanakan dari tanggal 27 November 2017 sampai dengan 03 Januari 2018. Kegiatan ini dilakukan sebanyak 4 kali, dimulai pada hari Senin tanggal 27 November 2017 di Aula Kelurahan Linggasari Kecamatan Ciamis untuk koordinasi dengan perangkat desa, bidan dan kader posyandu. Selanjutnya pada hari Sabtu tanggal 02 Desember 2017, hari Jum'at tanggal 15 Desember 2017 dan hari Sabtu tanggal 30 Desember 2017 di posyandu Cempaka Putih Desa Kolot Kelurahan Linggasari Kecamatan Ciamis.

Kegiatan pembinaan dan penyuluhan terhadap kader tentang pengelolaan posyandu dilakukan melalui metode ceramah dan diskusi dengan 11 orang kader posyandu Cempaka Putih. Instrumen penyuluhan yang digunakan berupa leaflet dan buku pegangan kader posyandu.

\section{HASIL DAN PEMBAHASAN}

Hasil dari kegiatan pengabdian masyarakat ini adalah pengetahuan kader tentang pengelolaan posyandu meningkat. Kader terlihat lebih aktif dan kompak dalam melengkapi sarana serta prasarana 
yang harus ada di posyandu. Selain itu juga, kader melengkapi administrasi di posyandu.

Agar posyandu melakukan fungsi dasarnya, dimana posyandu mempunyai daya ungkit yang sangat besar terhadap penurunan angka kematian bayi, angka kematian balita dan angka kematian ibu, maka perlu adanya upaya memantau dan mendorong tingkat perkembangan Posyandu. Melalui pembinaan dan penyuluhan terhadap kader tentang pengelolaan posyandu maka kualitas dan kemandirian posyandu meningkat.

\section{KESIMPULAN DAN SARAN}

Pembinaan dan penyuluhan terhadap kader tentang pengelolaan posyandu di Posyandu Cempaka Putih Kelurahan Linggasari Kecamatan Ciamis dari tanggal 27 November 2017 sampai dengan 03 Januari 2018 bertujuan meningkatkan pengetahuan kader tentang pengelolaan posyandu sehingga mampu meningkatkan kualitas dan kemandirian posyandu menjadi posyandu mandiri.

\section{UCAPAN TERIMA KASIH}

Ucapan terima kasih sebesar-besarnya penulis sampaikan kepada STIKes Muhammadiyah Ciamis yang telah memberikan dana sehingga pengabdian masyarakat ini bisa dilaksanakan. Tidak lupa penulis juga ucapkan terima kasih kepada:

1. H. Dedi Supriadi, S.Sos., S.Kep., Ners., M.Mkes, selaku Ketua STIKes Muhammadiyah Ciamis

2. H. Rudi Kurniawan, S.Kep., Ners., M.Kep, selaku Ketua Lembaga Penelitian dan Pengabdian Masyarakat STIKes Muhammadiyah Ciamis

3. Heni Heryani, SST., M.KM, selaku Ketua Program Studi D III Kebidanan STIKes Muhammadiyah Cimais

4. H. Ridwan, S.Pd.I., M.Si, selaku Kepala Kelurahan Linggasari Kec. Ciamis

5. Bidan Cucu Hudami, S.Tr.Keb, selaku bidan koordinator Puskesmas Pembantu Linggasari Kec. Ciamis

6. Para Kader Posyandu Cempaka Putih Desa Kolot Kelurahan Linggasari Kec. Ciamis

\section{DAFTAR PUSTAKA}

Ambarwati, Eny Retna dan Rismintari, Y Sriati. (2009). Asuhan Kebidanan Komunitas. Nuha Medika: Yogyakarta.

Dinas Kesehatan Kabupaten Ciamis. (2014). Profil Kesehatan Kabupaten Ciamis. Ciamis : Dinas Kesehatan Kabupaten Ciamis.

Dinas Kesehatan Kabupaten Ciamis. (2017). Profil Kesehatan Kabupaten Ciamis. Ciamis : Dinas Kesehatan Kabupaten Ciamis.

Kelurahan Linggasari. (2016). Profil Kelurahan Linggasari.

Kementerian Kesehatan RI. (2012). Posyandu Menjaga Anak dan Ibu tetap Sehat. Jakarta : Kementerian Kesehatan RI.

\section{LAMPIRAN}



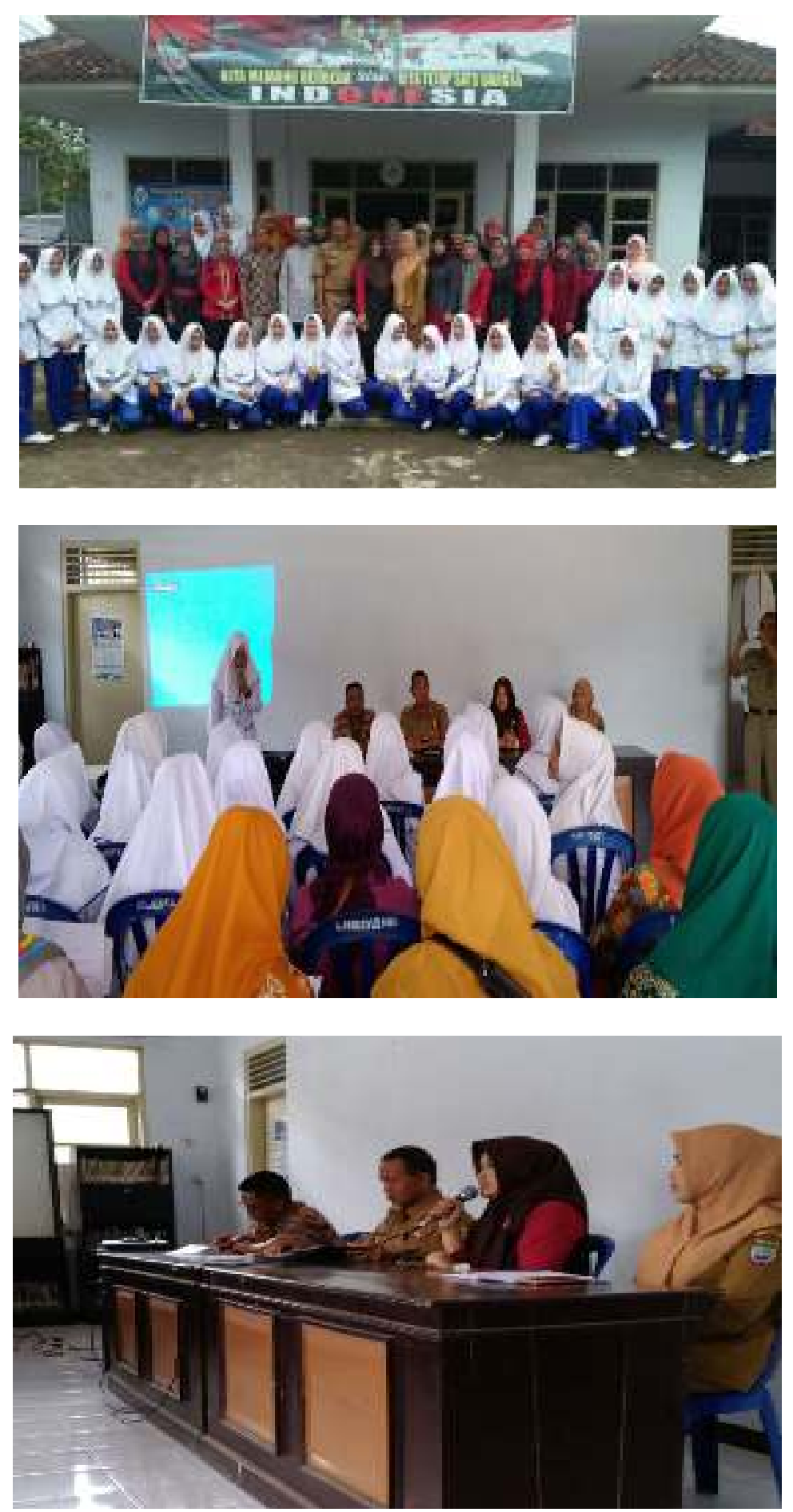

Gambar 1. Pertemuan dengan perangkat desa, bidan dan kader posyandu di Aula Kelurahan Linggasari 

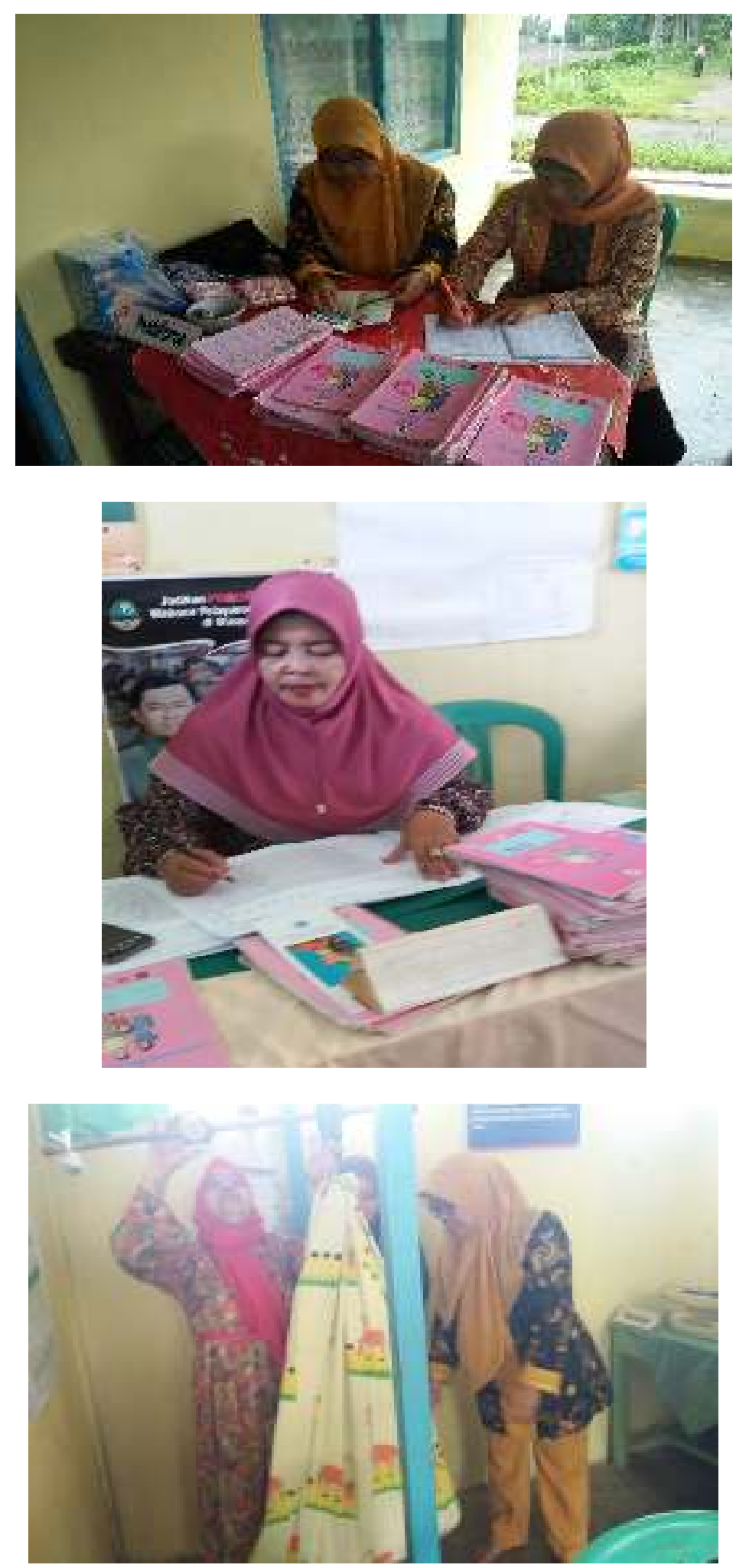

Gambar 2. Pembinaan dan penyuluhan terkadap kader di Posyandu Cempaka Putih Desa Kolot Kelurahan Linggasari 